\title{
Perceptions of smoking cessation among Glasgow's Chinese community
}

\author{
Williom Spence ${ }^{l}$, Lonyu Zhu ${ }^{1}$
}

\begin{abstract}
INTRODUCTION Health related needs and services are stratified by ethnicity in UK. The Chinese community is Scotland's second-largest minority ethnic group but a relatively under-researched one. This study aimed to explore the views and experiences of smoking cessation and related services among Chinese community members in Glasgow and to inform them about smoking cessation interventions.

METHODS This cross-sectional study was conducted in 2016 using a qualitative research method. Purposive sampling methods were used to recruit 15 Chinese community members in Glasgow. Semi-structured interviews were audio-recorded and data transcribed, translated, and thematically analysed.

RESULTS Many factors influenced participants' smoking: concern for personal health, advice from medical professionals, expenditure, family pressure, tobacco-control policies, nicotine dependence, self-efficacy, and acculturation. Smoking initiation and relapse were influenced by interpersonal relations, emotional factors, Chinese social norms, and acculturation. Barriers reported to accessing and participating in cessation services included: excessive or inflexible working hours, low confidence in cessation services, language barriers, cultural barriers and unsuitability of cessation services for Chinese smokers. Employing community resources, improving language support, working with cultural values, and accommodating degrees of acculturation may improve services and their uptake.

CONCLUSIONS Smoking-cessation services should consider the culture of this ethnic minority population to improve cessation uptake. Further investigation of this community's needs and expectations is needed to tailor smoking-cessation interventions for Chinese immigrants in Glasgow.
\end{abstract}

\author{
(20) \\ AFFILIATION \\ 1 University of Glasgow, \\ Glasgow, Scotland \\ CORRESPONDENCE TO \\ William Spence. School of \\ Medicine, Dentistry \& Nursing, \\ College of Medical, Veterinary \\ and Life Sciences, University of \\ Glasgow, 1 Lilybank Gardens, \\ G12 8RZ, Glasgow, Scotland. \\ E-mail: william.spence@ \\ glasgow.ac.uk

\section{KEYWORDS} \\ smoking, Chinese, immigrants, \\ cessation, Scotland
}

Received: 23 May 2017 Revised: 28 August 2017 Accepted: 23 September 2017

\section{INTRODUCTION}

Smoking is one of the biggest causes of preventable poor health and premature death, and kills more than 7 million people each year ${ }^{1}$. Around half of smokers will die prematurely from a smoking-related illness ${ }^{2}$; and smoking has been long viewed as a public-health problem in countries around the world, including Scotland and China.

About twenty percent of Scottish adults were smokers in 2014 , with similar rates for men and women, $23 \%$ and $21 \%$, respectively ${ }^{3}$. Tobacco use is associated with about: a quarter of all deaths and 56,000 hospital admissions each year in Scotland ${ }^{4}$. China has a deep-rooted cigarette-smoking culture ${ }^{5}$, for which the last (2010) Global Adult Tobacco Survey revealed a smoking prevalence of $52.9 \%$ and $2.4 \%$, among males and females, respectively ${ }^{6}$. Among rural migrants to urban locations in China, the prevalence in 2016 was more than double for females at $5.3 \%$ and lower for males at $46.7 \%{ }^{6}$.

The 2012 UK Integrated Household Survey (IHS) and 2012 GP Patient Survey (GPPS) indicated that cigarette smoking in the UK's Chinese population was $17 \%-21 \%$ for males and 6\%-7\% for females ${ }^{7}$. Smoking prevalence among 493 members of Glasgow's Chinese community showed male and female prevalence to be $21.9 \%$ and $1.6 \%$, respectively ${ }^{8}$. Chinese immigrants across the world have been observed to smoke less than their counterparts in China ${ }^{9,10}$.

The Chinese government has advised that smoking be prohibited $^{5}$ in public places, such as restaurants, bus 
stations, parks and offices. However, China has yet to meet the WHO Framework Convention on Tobacco Control (FCTC) guidelines ${ }^{11}$. Smoking initiation and maintenance is heavily influenced by: relatives' smoking ${ }^{12}$, peer influence ${ }^{13}$, culture $^{14}$, and genetic and environmental factors ${ }^{15}$. In the UK, attention to individual health, setting an example for children, and smoking expenditure, are amongst the top three motives for smoking cessation ${ }^{16,17}$. It is widely accepted that certain socio-demographic and socio-economic factors can affect smoking behaviour ${ }^{18}$. The health behaviour of immigrants may be expected to eventually reflect those of the host country's population through acculturation, and hence smoking cessation might follow this pattern ${ }^{19}$.

Smoking-cessation interventions were first implemented in the UK by the National Health Service in 1999, when the NHS National Institute of Clinical Excellence highlighted the need to reduce the prevalence of smoking amongst ethnic minority populations ${ }^{20}$. The factors that need to be taken into account in improving interventions tailored for ethnic minority groups are still disputed ${ }^{21}$. Convincing arguments have been made that it is important to adapt existing programmes for such groups ${ }^{22}$. Little research has been conducted on smoking within the UK Chinese population, and this might be due to a low level of bilingualism among researchers ${ }^{23}$. In addition, the stereotyping of Chinese immigrants as 'independent', 'closed', 'self-sufficient' and of 'poor English-speaking ability ${ }^{23}$ may also have contributed to the lack of research.

\section{Aims and objectives}

The overall purpose of this study was to explore the views and experiences of smoking cessation among Chinese-community members in Glasgow. The opinions of Chinese community members about smoking-cessation services were also explored.

\section{METHODS}

The qualitative approach used here focuses on the views and experiences of individuals in a natural setting ${ }^{24}$. The data reflect feelings, experiences and cognition that underlie and influence behaviour ${ }^{25}$. A semi-structured interview was used ${ }^{25}$ to ensure guidance of the discussion by the researcher ${ }^{26}$. It was used to focus on experiences of participants and to identify their smoking-related cognitions ${ }^{27}$.

There are about 11,000 Chinese in Glasgow ${ }^{28}$, and membership of the Chinese Community Development Partnership (CCDP), a non-profit organisation supporting this community, is around 450 people of Chinese origin. A general information questionnaire was developed, in English and Chinese, to collect basic demographic information on those interviewed and semi-structured interviews employed 11 initial questions, preceded by two pilot interviews.

Potential participants were Chinese community members aged 18-65 years old, normally living in Glasgow and who were currently smokers. Purposive sampling with snowballing was used in recruitment. Signed consent was collected from all participants, while seven participants were recruited via the CCDP and a further eight by snowballing.

\section{Table 1. Demographic details of participants}

\begin{tabular}{|c|c|c|c|c|c|c|c|c|}
\hline No. & Sex & Age Group & $\begin{array}{l}\text { Ilighest level of } \\
\text { education }\end{array}$ & $\begin{array}{l}\text { Working } \\
\text { Industry }\end{array}$ & $\begin{array}{l}\text { Years in } \\
\text { Glasgow }\end{array}$ & $\begin{array}{l}\text { Agestarted } \\
\text { smoking }\end{array}$ & $\begin{array}{l}\text { Smoking } \\
\text { history } \\
\text { (yrs) }\end{array}$ & $\begin{array}{l}\text { Average daily } \\
\text { consumption } \\
\text { (cigareltes) }\end{array}$ \\
\hline 1 & Male & $30-39$ & College & Commerce & $<5$ & $10-15$ & $8-10$ & $21-30$ \\
\hline 2 & Male & $30-39$ & High school & Catering & $>10$ & $10-15$ & $20-30$ & $21-30$ \\
\hline 3 & Female & $40-49$ & High school & Catering & $>10$ & $16-20$ & $20-30$ & $11-20$ \\
\hline 4 & Male & $30-39$ & High school & Catering & $>10$ & $21-25$ & $8-10$ & $1-10$ \\
\hline 5 & Male & $40-49$ & High school & Catering & $>10$ & $16-20$ & $11-20$ & $1-10$ \\
\hline 6 & Male & $20-29$ & High school & Catering & $5-10$ & $26-30$ & $<2$ & $1-10$ \\
\hline 7 & Male & $40-49$ & Junior school & Catering & $>10$ & $16-20$ & $20-30$ & $11-20$ \\
\hline 8 & Male & $50-59$ & Junior school & Catering & $>10$ & $16-20$ & $20-30$ & $11-20$ \\
\hline 9 & Male & $30-39$ & Junior school & Catering & $>10$ & $10-15$ & $11-20$ & $11-20$ \\
\hline 10 & Female & $20-29$ & Postgraduate & Commerce & $<5$ & $21-25$ & $5-7$ & $1-10$ \\
\hline 11 & Male & $20-29$ & Postgraduate & Engineering & $<5$ & $10-15$ & $5-7$ & $1-10$ \\
\hline 12 & Male & $20-29$ & Postgraduate & Financial & $<5$ & $16-20$ & $5-7$ & $1-10$ \\
\hline 13 & Male & $30-39$ & Postgraduate & Financial & $5-10$ & $16-20$ & $5-7$ & $21-30$ \\
\hline 14 & Male & $20-29$ & Postgraduate & Financial & $5-10$ & $10-15$ & $8-10$ & $1-10$ \\
\hline 15 & Male & $20-29$ & Undergraduate & Financial & $<5$ & $16-20$ & $5-7$ & $11-20$ \\
\hline
\end{tabular}


Qualitative data analysis software was used and the analysis involved the comparison of new data with analysed data; and the reduction of data through theme identification. Main themes and sub-themes were identified (Table 2 ) and verbatim quotations used to illustrate the core elements of respondents' accounts ${ }^{29}$ with the participant's number in brackets. The study was approved by the University of Glasgow's research ethics committee.

\section{RESULTS}

The main themes and sub-themes are presented in Table 2 and illustrative theme related interview data are presented in Box 1.

Table 2. Main themes and sub- themes of the results

\begin{tabular}{|c|c|c|}
\hline Main themes & & b-themes \\
\hline & $\begin{array}{l}\text { a. Concern for } \\
\text { personal health }\end{array}$ & $\begin{array}{l}\text { b. Advice from medical } \\
\text { professionals }\end{array}$ \\
\hline t - tocto & c. Expenditure & d. Family pressure \\
\hline smoking cessation & $\begin{array}{l}\text { e. Smoking } \\
\text { restriction policies }\end{array}$ & $\begin{array}{l}\text { f. Nicotine dependence } \& \text { self- } \\
\text { efficacy }\end{array}$ \\
\hline & 9. Acculturation & \\
\hline 2.Factors affecting & $\begin{array}{l}\text { a. Interpersonal } \\
\text { relations }\end{array}$ & b. Social norms \\
\hline initiation and relapse & $\begin{array}{l}\text { c. Emotional } \\
\text { factors }\end{array}$ & d. Acculturation \\
\hline 3. Barriers to access & a. Language barriers & b. Distrust of services \\
\hline $\begin{array}{l}\text { and participation in } \\
\text { smoking cessation } \\
\text { services }\end{array}$ & c. Inflexibility of serv & \\
\hline $\begin{array}{l}\text { 4. Recommendations } \\
\text { for increasing smoking }\end{array}$ & $\begin{array}{l}\text { a. Employing } \\
\text { community } \\
\text { resources }\end{array}$ & $\begin{array}{l}\text { b. Improving language } \\
\text { support }\end{array}$ \\
\hline $\begin{array}{l}\text { cessation services' } \\
\text { accessibility }\end{array}$ & $\begin{array}{l}\text { c. Working with } \\
\text { cultural values } \\
\text { related to smoking }\end{array}$ & $\begin{array}{l}\text { d. Acculturation and planning } \\
\text { of targeted interventions }\end{array}$ \\
\hline
\end{tabular}

\section{Factors affecting smoking cessation among Chinese community members in Glasgow}

\section{1a. The concern for personal health}

Most participants reported that the main reason for quitting was a health problem related to smoking, but most health concerns seemed to reflect immediate concerns:

'Cigarettes make me uncomfortable. It seemed that my chest pained me then. Another reason may be for saving money (laugh). OK... it's a joke.' (P6)

There were few references to long-term consequences of smoking-related health problems:

'It is well-known that long-term smoking can may cause lung cancer.' (P11)

\section{Box 1. Themes and related interview data}

Factors affecting smoking

- Cough, the main reason is cough... I know it is not healthy. It is the main reason. (P2)

- The most terrible thing is printing large health warnings on cigarette packing abroad has affected me. (P3)

- I have limited supply of cigarettes brought from China... price here is much higher, that seems difficult to accept for me... like four times than that in China. (P13)

- Now I have a family, I must take care of my family, so I smoke less. (P8)

- It may be related to indoor smoking ban, because I live high places, I must go to downstairs to smoke, the winter is particularly cold... (P15)

- I tried to quit smoking in China, too many social events that I am not in the position of quitting anyway... There is not any social pressure regards of smoking here (in Scotland), thus I feel it is a good chance for me to smoke less. (PI)

Factors affecting initiation and relapse

- The main reason is that I have nothing to do, I stay up late when I work in UK. (PI 1)

- I didn't have a job during that period of time (when I came to Glasgow). I drank at home all day and smoked again. (PI)

- There is too much trouble in my life, I feel relieved from my worries while smoking. (P3)

- In China, I smoked only when I went to the pubs... (in) Britain I smoked a pack every day. Since there are a lot female smokers, it will not be so strange and alternative. ( $\mathrm{PlO}$ )

Barriers to access and participation in smoking cessation services

- In my mind, there are few advertising materials containing relevant images due to some smokers cannot read either Chinese or English. (P12)

- In my experiences, in our group quitting thing, 9 out of 10 cannot quit smoking in the end...Actually I don't have good advices, it all depends on self-efficacy, I feel suggestions and advices have no use at all. It is all personal decision. (Pl)

- I don't really know any single thing about any smoking cessation service that runs in Glasgow. Nobody ever mentioned to me. I don't know anything myself either. ( $\mathrm{P} 11$ )

Recommendations for increasing smoking cessation services' accessibility

- I think most of the Chinese people in Glasgow usually social together in a community group. If the government can cooperate with community groups, I feel in that way it might works better than normal propaganda. (P11)

'First of all, it's not good for lung for all people. Another is that will increase in the probability of breast cancer for the female.' (P10)

Several participants recalled receiving health-risk information from tobacco health-warnings in the UK and these much improved their motivation for smoking cessation. The concern for personal health plays an important role in affecting smoking cessation among Chinese community members in Glasgow. The considerable influence of healthrisk information may have considerable implications for cessation efforts.

\section{Advice from medical professionals}

Respondents reported that general practitioners (GPs) in the 
UK play an important role in discouraging smoking:

'Every single doctor told me not to smoke, they recommended me to use nicotine patches for smoking cessation. It's all free from GP now.' (P9)

However, this advice did not seem to be well-accepted by certain participants:

'Well, they are doctors, they would always suggest you not to smoke...I still smoke anyway.' (P4)

Some participants reported that Chinese smokers ignore local cessation services, owing largely to their long or inflexible working hours, and low confidence in the services. Suggestions provided by medical professionals were regarded as important in smoking cessation decisions.

\section{1c. Expenditure}

The majority of participants reported that the price of cigarettes in the UK was an important motivating factor to quit and many preferred to smoke cheaper Chinese cigarettes: 'Each person can [enter UK with] two packages of cigarette. Some, for example, will take two as they come here and sell it to in our Chinese Internet Community Forum. The price is higher than Chinese price but much lower than here.' (P3)

However, some participants preferred more expensive local cigarettes, reflecting a long-established habit. One participant suggested that the effect of high cigarette prices in the UK on smoking-cessation behaviour is related to income levels:

'High price (of cigarettes) only effects people with low income, people with higher income are not that price sensitive to it.' (P14)

A range of views was expressed about the significance of cigarette prices, reflecting personal habits and income level.

\section{1d. Fomily pressure}

A number of married participants noted that the concern of their relatives was an important motivation for quitting:

'The first time I want to quit is because that I ran into my parents and relatives when smoking.' (P1)

Family objection to participants' smoking may have some impact on the decision to stop.

\section{1e. Smoking restriction policies}

Basically, all smokers in our research study accepted smoking restriction rules in the UK:

'Second it is forbidden in public places...Local people always show a better character and they will go to the special areas for smoking. But in China, people would smoke either at the table or some public occasions.'(P13)
Many participants reported limitations on their smoking indoors, but they supported the prohibition of smoking in their homes:

'Oh, my elder family adults and kids around you will draw you pressure. Nobody smokes at home, if you want to smoking, you have to go outside.' (P1)

One participant referred to legal penalties to exemplify the extent of the anti-smoking law in the UK, which he contrasted with the situation in China.

'In Glasgow city centre somewhere, I throw the cigarette butt on the floor and I didn't pay attention like I was in China before, but the police caught me and fined me some good money.' (P11)

The effectiveness of strong government policies restricting smoking in the UK were affirmed by many participants, perhaps in contrast to a weaker policy in China.

\section{If. Nicotine dependence and self-efficacy}

Many participants reported their lower nicotine dependence to be predictive of being able to quit; and self-efficacy - the belief in one's ability to succeed in cessation - played an important role in smoking-cessation decision making:

'I can quit smoking at any time if I want to. I am not addicted.' (P6)

'I can quit it at any time, if I find a girlfriend, I will quit it immediately. Because I have not higher nicotine dependence and can control by myself.' (P4)

However, two males linked their lower nicotine dependence to maintenance, and not to quitting:

'No, I never try to quit smoking. I think I could stop smoking as I am not that addicted. I can control, I do not control deliberately, in fact, my parents do not know that I smoke.' (P15)

Although participants held different views about whether lower nicotine dependence affects smoking cessation, the effects of self-efficacy related to smoking cessation may have implications for targeting smoking-cessation interventions to more dependent smokers.

\section{Acculturation}

Only one-third of participants had tried to quit smoking while in China. However, most participants had tried to quit smoking after migrating. Around two-thirds of the participants showed intent to quit smoking:

'It is not healthy; I am thinking about quitting. My wife hates me for it. She always says that I can save a lot of money by quitting. smoking:' (P8)

Acculturation may promote cessation among Chinese people in Glasgow. 
2 Factors affecting initiation or relapse of smoking among Chinese community members in Glasgow

\section{2a. Interpersonal influence}

Most participants reported that someone in their social circle influenced their initiation to smoking:

'I thought it was interesting then, I watched adults smoking and followed them. My parents smoked...I stopped smoking for 8 years. But when I came here, I felt bored and other people around me smoked, I smoked with them.' (P1)

Where Chinese community members are not fully integrated within the local population then their home-country smoking rate may be slower to change to that of their present community.

\section{2b. Social norms}

The Chinese viewpoint of cigarettes as a social-connection builder was reported by many respondents:

'Smoking has become a habit, or a social way in China. I think the latter counts for greater proportion. For example, if you find yourself difficult to join in a group of people who smoke for topics and interactions, a cigarette would be of great help to resolve the embarrassment. In fact, most of the foreigners...will ask for cigarettes and fire, which seems to me a way to get closer to strangers.' (P13)

Positive cultural values towards smoking were recognized by participants, which suggests the need for a change in cultural beliefs and behaviour, and a recognition of this factor by cessation services.

\section{2c. Emotional factors}

Around two-thirds of the respondents mentioned curiosity and fun as a motivator to starting smoking:

'I start smoking as early as in my twenties. At first I was curious about tobaccos and saw it somehow cool. It was also due to the college entrance examination and other tests.' (P11)

Two participants believed that smoking helped them to decrease the boredom related to the societal integration challenges faced by immigrants:

'I feel bored, starting smoking for killing time...there are the lack of recreational activities among immigrants.' (P6)

The main causes of relapse were the belief that smoking reduced stress and promoted relaxation:

'Because I can't sleep till two o'clock at midnight due to heavy stress of work. Then I smoked outside and chat in the place me and my friends live in. It then becomes a habit and I will come out at a fixed time.' (P10)
Employment-related stress may be a relevant factor to consider in cessation and the need for advice on stress management.

\section{2d. Acculturation}

Acculturation may promote cessation among Chinese people in Glasgow. Many respondents commented on the high smokingprevalence among Chinese females in Glasgow compared with those in China:

'When I come here I find that there are many girls also smoking... I think it is due to the fact that it is more equal between men and women.' (P1)

One participant who lived in Glasgow for more than 20 years and was proficient in English reported that acculturation influenced her smoking:

'Every time I return back to China, I would not be walking in the street to smoke. It is more comfortable to find a secret corner to smoke rather than be in the face of others.' (P10)

The societal view about women smoking in China is clearly identified here.

\section{Barriers to access and participation in smoking cessation services}

\section{3a. Language barriers}

Older smokers, who were not proficient in English, reported a reluctance to use existing services:

'It is difficult for me to go to someone speaking English. I am not willing to use that services...mainly due to the language barriers.' (P8)

Chinese community members considered lack of English as a considerable problem in accessing cessation and health services in general.

\section{3b. Doubts of the effectiveness of services}

Several participants questioned the value of replacement therapy:

I know certain smoking cessation services provided by the government, but I did not want to go there. I think there is no way for me to quit. I mean that I do not want to waste time on it, it is a waste of time for me as well as for others.' (P8)

Self-control was seen as important in achieving smoking cessation. Participants held relatively negative views of smoking cessation services, and this may have implications for cessationservices development.

\section{3c. Inflexibility of services}

Most respondents were referred to smoking-cessation services by their GP, but most did not access them. Three participants cited long working hours as the cause: 
'My working hours are excessive or inflexible, I do not have time to go to smoking cessation department regularly to receive treatment.' (P12)

Younger males in this research study had little knowledge of cessation services. Smoking-cessation services will need to be accessible by this population sub-group if they are to be effective.

\section{Recommendations for increasing smoking cessation services' accessibility}

\section{4a. Employing community resources}

The majority of participants believed that promoting the dissemination of information on smoking cessation was essential to building relationships with the local Chinese community:

'As far as I know some churches and welfare organizations will gather the smokers to do something like divine services and they will exchange some experiences in quitting smoking. This is a really good way to promote smoking cessation services by building relationships with the local communities.' (P13)

\section{4b. Improving language support}

More language support in cessation information was mentioned frequently by participants:

It says in traditional Chinese in the store. It is a store selling e-cigarettes...Traditional Chinese slogan is more familiar. If it is only in English, I won't notice. It also has a picture of cigarette. That kind of attract me as well.' (P15)

\section{4c. Working with cultural values related to smoking}

Two participants noted that cessation services need to consider cultural values:

'As you know, Chinese will give cigarette to each other as they meet. They will give you cigarette if you can smoke and sometimes even you cannot smoke. So, social smoking is an important element for smoking. Maybe we can start from transforming social norms.' (P15)

Another respondent suggested the need to promote confidence in cessation preparations among Chinese community members.

\section{4d. Acculturation and planning of targeted interventions}

Several participants commented on the need to promote acculturation given the likely influence on cessation behaviour: 'Chinese in Glasgow always have too much of stress, from the family, from the long working hours. In order to deal with this sort of stress, people usually turn such thing like smoking, gambling, drinking. I suggest that Chinese smokers should be encouraged to participate in some social activities or sports to enrich their life.' (P15)

'Some girls I know consider smoking is a symbol of gender equity.' (P10)

\section{DISCUSSION}

This study found that one-third of participants had tried to quit smoking while living in China, reflecting the Jiang et al. ${ }^{30}$ finding that $75.6 \%$ of a sample of smokers in China had no plan to quit and $52.7 \%$ had never tried. Here, most participants reported smoking-related health problems and medical advice as the main reasons for quitting, and the latter was found to be the most commonly cited smoking-cessation trigger in China ${ }^{31}$. Few studies have reported the importance of physician advice for quitting in China and this may reflect the high smoking prevalence, $21 \%-61 \%$, amongst Chinese physicians ${ }^{32}$.

On migration to Glasgow, most participants here had tried to quit with various triggers cited. Around two-thirds intended to quit at the time of interview; with concern for individual health and the advice from health professionals, being the top reasons cited. This may reflect UK smokers' greater knowledge of smoking-related health risks and higher motivation to quit than their counterparts in China ${ }^{33}$.

In the UK, cigarette-pack health warnings increased motivation to quit and were found to be more effective than equivalent Chinese warnings ${ }^{34}$. Such health-risk information may be an important consideration for this community, when cessation is promoted. General practitioners (GPs) here are important in discouraging smoking, with $36 \%$ of a sample of UK smokers finding that their advice prompted quit attempts ${ }^{35}$. Excessive or inflexible working hours and low confidence in smoking-cessation services led to the low interest in cessation services in the community here, and this has not been reported before. The cost of cigarettes is known to be a trigger for cessation in the UK, but is the least significant motivation to quit in China ${ }^{16,36}$ where tobacco is cheap. A barrier to quitting here was the availability of cheaper imported Chinese cigarettes, but the link between cigarette type and cessation has not been previously well explored.

In the UK, marriage and co-habitation are significantly associated with past quit attempts ${ }^{37,38}$. In this study, most married participants indicated that the concern for relatives was an important quit motivator on moving to Glasgow. Chinese immigrants in the UK were more aware of, and sensitive to, the risks of second-hand smoke than when in China ${ }^{39}$. The impact of smoking on offspring was cited here as a quit trigger, and 
this has been identified ${ }^{40}$. The collectivist culture of China may promote more consideration for others' views in the cessation decision than individualistic cultures.

Lower nicotine dependence and higher self-efficacy have been associated with increased quit-attempt rates and longterm cessation in the $\mathrm{UK}^{41}$; here many participants reported that their lower nicotine dependence was predictive of being able to make a quit attempt. However, two males reported low nicotine dependence and a negative attitude to smoking cessation, but not to quitting. This had not been previously identified in this group, but may be of importance in cessation support.

The participants' higher prevalence of cessation attempts on migration to Glasgow is supported by the literature, which suggests that acculturation is a considerable determinant of smoking cessation behaviour among immigrants ${ }^{18,42}$. Twothirds of the participants reported that Chinese immigrant smokers had adopted the UK smoking pattern, and smoking among the individual's social circle is a well-established reason for initiation or relapse in smoking ${ }^{13,43,44}$. One female participant reported that a colleague smoking prompted her relapse. The level of acculturation may be an issue for cessation-programme planners to consider, as will be the use of the workplace setting to promote cessation, particularly where the workforce is largely composed of Chinese immigrants. The social role of cigarette smoking among Chinese people reflects wellestablished social norms ${ }^{39,45}$, and social factors were influential here in triggering relapse in participants while in the UK.

Participants rarely used smoking-cessation services in Glasgow, despite their general effectiveness ${ }^{46}$. Uptake of NHS stop-smoking services by Chinese immigrants in 2015 was below a quarter that of other populations ${ }^{47}$, and this may reflect doubts about pharmacotherapy and practicalities of service access $^{48,49}$. Language, distrust, and inflexibility of services were barriers to cessation-service use; and Liu et al. ${ }^{50}$ emphasized that high-quality language interpretation must be professional and trusted, to enable access to cessation services.

Most participants did not access cessation services to which they had been referred to by their GPs. Several reported that discussion with a GP had prompted a quit attempt, but this became impractical due to their long working hours; similar findings exist in the literature ${ }^{51}$. Chinese smokers in the UK were mainly unaware of NHS smoking-cessation services, and this emphasizes the significance of developing culturallyappropriate measures to increase awareness and access to cessation $^{17}$.

The use of community resources can dramatically increase accessibility $^{52}$ through the development of trust. Community lay health workers may be effective in improving the uptake of cessation services ${ }^{53}$, and participants here believed that bilingual promotional information on cessation services was essential in building good relationships with the local Chinese community. Using and evaluating community resources to increase accessibility might be regarded as a useful basic principle for cessation-service planners to consider ${ }^{52}$.

Compatibility of health-promotion information with the belief system of targeted populations plays an important role in enabling attitudinal and behavioural changes related to smoking $^{52}$; resolving smokers' distrust of services poses a challenge for health promoters ${ }^{51}$. Here, most participants reported no confidence in cessation preparations, believing personal willpower as a more effective approach. To be more effective in assisting Chinese smokers to quit, it is essential for service providers to understand cultural values related to cigarette smoking ${ }^{53}$.

\section{CONCLUSIONS}

Improving health information and education among Chinese community members in Glasgow may be important in improving cessation-services uptake. Improved language support should be considered, including the use of Chinese and English in promotional material, together with the targeting of families and groups that could support smokers to quit. Improved information relating to pharmacotherapy may increase nicotine-replacement-therapy uptake, as might be the use of Chinese community resources to promote cessation. A settings approach to cessation, and consideration of the antisocial hours of work, common in the catering industry, may improve cessation-service engagement.

\section{REFERENCES}

1 World Health Organization. Tobacco and its environmental impact.Available at: http://apps.who.int/iris/bitstre am/10665/255574/1/9789241512497-eng.pdf?ua=1 (accessed July 2017).

2. World Health Organization. Report on Tobacco Taxation in the United Kingdom. Available at: http://www.who.int/tobacco/training/ success_stories/en/best_practices_united_kingdom_taxation.pdf (accessed May 2016).

3. ASH Scotland. Information about Tobacco and Health: Statistics: Smoking Rates. Available at: http://www.ashscotland.org.uk/ ash/4320 (accessed May 2016).

4. Reid, J., Hecht, G. Smoking Ready Reckoner, Scot PHO. 2012. Available at: http://www.scotpho.org.uk/publications/reports-andpapers/868-smoking-ready-reckoner (accessed May 2016).

5. Han, Z. L.: Cigarette smoking in China. Health Education 2012, 112(4): 312-318.

doi: 10.1108/09654281211237144 
6. Liu Yao, Gao Jian, Shou Juan, Xia Huiling, Shen Yao, Zhu Shanzhu, Pan Zhigang. The Prevalence of Cigarette Smoking Among Rural-toUrban Migrants in China: A Systematic Review and Meta-Analysis. Substance Use \& Misuse 2016, 51(2): 206-215. doi: 10.3109/10826084.2015.10929879

7. Aspinall, P. J., Mitton, L. Smoking prevalence and the changing risk profiles in the UK ethnic and migrant minority populations: implications for stop smoking services. Public Health 2014, 128: 297306.

doi: 10.1016/j.puhe.2013.12.013

8. Liao, X. H., Mcllwaine, G. The health states and health needs of a Chinese population in Glasgow. Scottish Medicine Journey 1995, 40: $77-80$. doi: $10.1177 / 003693309504000306$

9. Li N., Tuomilehto J., Dowse G., Alberti K. G., Zimmet P., Min Z., Chitson P., Gareeboo H., Chonghua Y., Fareed D. Electrocardiographic abnormalities and associated factors in Chinese living in Beijing and in Mauritius. Br Med J 1992, 304: 1596-1601. doi: 10.1136/bmj.304.6842.1596

10. Hsu-Hage Bridget H.-H., Wahlqvist Mark L. Cardiovascular risk in adult Melbourne Chinese. Australia Journal Public Health 1993, 17: 306-313.

doi: 10.1111/j.1753-6405.1993.tb00160.x

11. Chinese Association on Tobacco Control. The Harms of Tobacco: Science and Myths 2010. Beijing.

12. Scherrer, J. F., Xian, H., Pan, H., Pergadia, M. L., FMadden, P. A., Grant, J. D., ESartor, C., Haber, J. R., Jacob, T. and KBucholz, K. Parent, sibling and peer influences on smoking initiation, regular smoking and nicotine dependence: Results from a genetically informative design. Addictive Behaviours 2012, 37(3): 240-247.

doi: 10.1016/j.addbeh.2011.10.005

13. Harakeh, Z., Vollebergh, W. A.: The impact of active and passive peer influence on young adult smoking: An experimental study. Drug and Alcohol Dependence 2011, 121(3): 220-223.

doi: 10.1016/j.drugalcdep.2011.08.029

14. Reveles, C. C., Segri, N. J. and Botelho, C.: Factors associated with hookah use initiation among adolescents. Jornal de pediatria 2013, 89(6): 583-587.

doi : 10.1016/j.jped.2013.08.001

15. Rani, M., Bonu, S., Jha, P., Nguyen, S. N. and Jamjoum, L.Tobacco use in India: prevalence and predictors of smoking and chewing in a national cross sectional household survey. Tobacco Control 2003, 12(4): e4. doi: 10.1136/tc.12.4.e4

16. Baha, M., Le, F. A.: Smokers' reasons for quitting in an anti-smoking social context. Public Health 2010, 124: 225-231. doi: 10.1016/j.puhe.2010.02.011

17. Hammond, D., Fong, G. T., Mcneill, A., Borland, R. and Cummings, K. M. Effectiveness of cigarette warning labels in informing smokers about the risks of smoking: findings from the International Tobacco Control (ITC) Four Country Survey. Tob Control 2006, 15(3): 19-25. doi: 10.1136/tc.2005.012294

18. Reiss, K., Lehnhardt, J. and Razum, O. Factors associated with smoking in immigrants from non-western to western countries - what role does acculturation play? A systematic review. Tobacco Induced Diseases 2015, 13: 1-23. doi: 10.1186/s12971-015-0036-9

19. Razum, O., Twardella, D. Time travel with Oliver Twist - towards an explanation for a paradoxically low mortality among recent immigrants. Tropical Medicine \& International Health 2002, 7(1): 4-10. doi: 10.1046/j.1365-3156.2002.00833.x

20. Department of Health. New NHS Smoking Cessation Service (Health Service Circular) 1999, London: Department of Health.

21. Aboud, F. Virtual Special Issue Introduction: Health Behaviour Change. Social Science and Medicine 2010, 71(11): 1897-1900. doi: 10.1016/j.socscimed.2010.09.002

22. Bhopal, R. S. The public health agenda and minority ethnic health: a reflection on priorities. Journal of the Royal Society of Medicine 2006, 99: 58-61. doi: $10.1258 / \mathrm{jrsm} .99 .2 .58$

23. Fountain, J., Hicks, J. Delivering race equality in mental health care: Report on the findings and outcomes of the community engagement programme 2005-2008, 2013. Preston: University of Central Lancashire.

24. Mays, N., Pope, C. Qualitative research: Rigour and qualitative research. BMJ 1995, 311: 109-112. doi: 10.1136/bmj.311.6997.109

25. Creswell, J. W., Plano Clark, V. L. Designing and conducting mixed methods research 2011. London: Sage.

26. Morgan, D. L. Focus group as qualitative research 1997. London: Sage.

27. Mccaslin, M. L., Scott, K. W.: The five-question method for framing a qualitative research study. The qualitative Report 2003, 8: 447461. Available at: http://nsuworks.nova.edu/cgi/viewcontent. cgi?article $=1880 \&$ context=tqr (accessed May 2016).

28. Glasgow City Council. Regeneration and the Economy Policy Development Committee, Report by Executive Director of Development and Regeneration Services, 2011 Census - Key Statistics. 2013. Available at: https://www.glasgow.gov.uk/CHttpHandler. ashx?id=17543\&p=0 (accessed May 2016).

29. Green, J., Thorogood, N. Qualitative methods for health research (Series: Introducing qualitative methods) 2009. London: Sage.

30. Jiang, Y., Marshall, T. E., Fong, G. T. and Li, Q. Quitting smoking in China: findings from the ITC China Survey. Tobacco Control 2010, 19(2): 12-17. doi: $10.1136 /$ tc.2009.031179

31. Im, P. K., McNeill, A., Thompson, M. E., Fong, G. T., Xu, S., Quah, A. C. K., Jiang, Y. and Shahab, L. Individual and interpersonal triggers to quit smoking in China: a cross-sectional analysis. Tobacco Control 2015, 24: 40-47.

doi: 10.1136/tobaccocontrol-2014-052198

32. Smith, D. R., Zhao, I., Wang, L. Tobacco smoking among doctors in mainland China: a study from Shandong province and review of the literature. Tob Induc Dis 2012, 10: 14-31. doi: 10.1186/1617-9625-10-14

33. Yang, J. L., Hammond, D., Driezen, P., Fong, G. T. and Jiang, Y. Health knowledge and perception of risks among Chinese smokers and non-smokers: findings from the Wave 1 ITC China Survey. Tob Control 2010, 19(2): 18-23.

doi: $10.1136 /$ tc.2009.029710

34. Fong, G. T., Hammond, D., Jiang, Y., Li, Q., Quah, A. C. K., Driezen, P. and Yan, M. Perceptions of tobacco health warnings in China compared with picture and text-only health warnings from other countries: an experimental study. Tob Control 2010, 19(2): 69-77. doi: $10.1136 /$ tc. 2010.036483

35. Murray, R. L., Lewis, S. A. and Coleman, T. Unplanned attempts to quit smoking: missed opportunities for health promotion? Addiction 2009, 104: 1901-1909. 
doi: 10.1111/j.1360-0443.2009.02647.x

36. Ranson, M. K., Jha, P. and Chaloupka, F. J. Global and regional estimates of the effectiveness and cost-effectiveness of price increases and other tobacco control policies. Nicotine Tob Res 2002, 4: 311319.

doi: $10.1080 / 14622200210141000$

37. Caponnetto, P., Polosa, R. Common predictors of smoking cessation in clinical practice. Respir Med 2008, 102: 1182- 1192. doi: 10.1016/j.rmed.2008.02.017

38. Lee, C. W., Kahende, J. Factors associated with successful smoking cessation in the United States, 2000. Am J Public Health 2007, 97: 1503-1509. doi: 10.2105/ajph.2005.083527

39. FitzGerald, J. M., Poureslami, I., and Shum, J. Assessing beliefs and risk perceptions on smoking and smoking cessation in immigrant Chinese adult smokers residing in Vancouver, Canada: a crosssectional study. BMJ 2015, 5: 77-90. doi: 10.1136/bmjopen-2014-006435

40. Rosen, L. J., Noach, M. B., Winickoff, J. P. and Hovell, M. F.Parental Smoking Cessation to Protect Young Children: A Systematic Review and Meta-analysis. Pediatrics 2012, 1(129): 141-152. doi: 10.1542/peds.2010-3209

41. A Hyland, R Borland, Q Li1, H-H Yong, A McNeill, G T Fong, R J O'Connor, K M Cummings. Individual-level predictors of cessation behaviours among participants in the International Tobacco Control (ITC) Four Country Survey. Tob Control 2006, 15: iii83-94. doi: 10.1136/tc.2005.013516

42. Thun, M., Peto, R., Boreham, J. and Lopez, A.D. Stages of the cigarette epidemic on entering its second century. Tob Control 2012, 2(21): 96-101. doi: 10.1136/tobaccocontrol-2011-050294

43. Chezhian, C., Murthy, S., Prasad, S., Kasav, J. B., Mohan, S. K., Sharma, S., Singh, A. K., Joshi, A. Exploring Factors that Influence Smoking Initiation and Cessation among Current Smokers. Journal of Clinical and Diagnostic Research 2015, 9(5): 8-12. doi: 10.7860/JCDR/2015/12047.5917

44. Jeganathan, P. D., Hairi, N. N., Sadat, N. A. and Chinna, K. Smoking Stage Relations to Peer, School and Parental Factors among Secondary School Students in Kinta, Perak. Asian Pacific Journal of Cancer Prevention 2013, 14(6): 3483-3489. doi: 10.7314/APJCP.2013.14.6.3483

45. Pan, Z. Socioeconomic predictors of smoking and smoking frequency in urban China: evidence of smoking as a social function. Health Promote Int. 2004, 19: 309-315. doi: 10.1093/heapro/dah304

46. Ferguson Janet, Bauld Linda, Chesterman John, Judge Ken.The English smoking treatment services: one-year outcomes. Addiction 2005, 100: 59-69. doi: 10.1111/j.1360-0443.2005.01028.x

47. Department of Health. Statistics on NHS Stop Smoking Services in England 2014 to March 2015, Lifestyles Statistics 2015. London: NHS Health and Social Care Information Centre.

48. Bush, J., White, M., Kai, J., Rankin, J. and Bhopal R. Understanding influences on smoking in Bangladeshi and Pakistani adults: community based, qualitative study. British Medical Journal 2003, 326: 962-965. doi: 10.1136/bmj.326.7396.962

49. White, M., Bush, J., Kai, J., Bhopal, R. and Rankin, J. Quitting smoking and experience of smoking cessation interventions among UK Bangladeshi and Pakistani adults: the views of community members and health professionals. Journal of Epidemiology and Community Health 2006, 60: 405-411. doi: 10.1136/jech.2005.040345

50. Liu, J. J, Davidson, E., Bhopal, R. S., White, M., Johnson, M. R. D., Netto, G., Deverill, M. and Sheikh, A. Adapting health promotion interventions to meet the needs of ethnic minority groups: mixedmethods evidence synthesis. Health Technology Assessment 2012, 16(44): 1-469. doi: 10.3310/hta16440

51. Begh, A. G., Aveyard, P., Upton, P., Bhopal, R. S., White, M., Amos, A., Prescott, R. J., Bedi, R., Barton, P. M., Fletcher, M., Gill, P., Zaidi, O. and Sheikh, A.: Experiences of outreach workers in promoting smoking cessation to Bangladeshi and Pakistani men: longitudinal qualitative evaluation. BMC Public Health 2011, 11: 452-467.

doi: 10.1186/1471-2458-11-452

52. Netto, G., McCloughan, L. and Bhatnagar, A. How can health promotion interventions be adapted for minority ethnic communities? Five principles for guiding the development of behavioural interventions. Health Promotion International 2010, 25(2): 248-257. doi: 10.1093/heapro/daq012

53. Lewin, S. A., Dick, J., Pond, P., Zwarenstein, M., Aja, G., van Wyk, B., Bosch- Capblanch, X. and Patrick, M. Lay health workers in primary and community health care: Cochrane systematic review. International Journal of Epidemiology 2005, 34: CD004015. doi: 10.1002/14651858.CD004015.pub2
ACKNOWLEDGEMENTS

The assistance of Glasgow's Chinese Community Development Partnership in recruiting participants is acknowledged, as is the contribution of al participants to the study.

CONFLICT OF INTERESTS The authors have completed and submitted the ICMJE Form for Disclosure of Potential Conflicts of Interest and none was reported.

FUNDING

There was no source of funding for this research.

PROVENANCE AND PEER REVIEW

Not commissioned; externally peer reviewed 